\title{
A relação entre ser humano e natureza a partir de Schelling e Moltmann
}

\section{The relation between human being and natu- re according to Schelling and Moltmann}

\author{
Gabriel Almeida Assumpção \\ Doutorando em filosofia pela UFMG, bolsista pela \\ FAPEMIG, Professor assistente da FAJE, \\ Fabrício Veliq \\ Doutor em teologia pela FAJE, Doctor in Theology - \\ KU LEUVEN e bolsista pela CAPES
}


Este artigo é dedicado à Andréa Ruas Veliq. 
Resumo: O presente artigo tem o intuito de colocar em diálogo as perspectivas teológicas do pensamento de Moltmann e a filosofia da natureza de Schelling, mostrando os pontos convergentes e divergentes entre os dois pensadores. Como ponto divergente, Schelling valoriza a concepção da natureza como algo além de meros produtos naturais (organismos, gases, formações geológicas), mas também como produtividade, como um todo, irredutível a mero instrumento de dominação humana. Moltmann, por sua vez, pensa a natureza como Criação de Deus, e o ser humano como parte mais frágil em todo esse processo dado seu lugar na ordem da Criação, ideia que não se encontra na filosofia da natureza de Schelling. Como ponto de convergência, é possível perceber que tanto Schelling quanto Moltmann fazem uma grande crítica ao mecanicismo e à concepção utilitária da natureza trazida pela filosofia Moderna.

Palavras-chave: Moltmann; Natureza; Ser Humano; Schelling.

Abstract: This paper proposes a dialogue between Moltmann's theological perspectives and Schelling's philosophy of nature, shedding light into the resemblances and differences between both thinkers. As a point of divergence, Schelling values the conception of nature as something beyond mere natural products (organisms, gases, geological formations), but also as productivity, as a whole, irreducible to a mere instrument of human domination. Moltmann, on his turn, thinks nature as God's Creation, and human being as the frailest part in this process, given his place in the order of Creation (a conception that is not found in Schelling's philosophy of nature). As a point of convergence, it is possible to notice that both Schelling and Moltmann criticize mechanicism and an utilitarian conception of nature brought by Modern philosophy.

Keywords: Moltmann; Human Being; Nature; Schelling.

\section{Introdução}

$\mathbf{U}$ ma dificuldade no estudo de Friedrich Schelling (17751854) consiste na diversidade dos temas que aborda, de maneiras distintas ao longo de sua obra. A questão dos mitos, por exemplo, é abordada em 1793, no seu primeiro texto filosófico publicado, Sobre os Mitos; em 1802-1805, nos cursos de Fi- 
losofia da Arte, e posteriormente, em seus cursos de Filosofia da Mitologia (1837/1842). No caso da natureza, há uma elaboração já no estudo de Schelling sobre os diálogos Timeu e Filebo, datado de aproximadamente 1794. Em seguida, há publicação de várias obras sobre filosofia da natureza durante dez anos, e uma retomada mais humilde em escritos posteriores.

A filosofia da natureza de Schelling, desenvolvida especialmente entre 1797 e 1806, tem sido estudada com a devida atenção (BEISER, 2002; CHO, 2008; GRANT, 2006; 2010; HEUSER-KESSLER, M.-L.; JACOBS, W.; 1994; MATTHEWS, 2011; SCHLANGER, 1966; SHAW, 2010, 2016; WIRTH, 2003), inclusive no Brasil (ASSUMPÇÃO, 2015; 2017; BARBOZA, 2005; GONÇALVES, 2005; 2015). Nota-se a intenção crescente de estudar Schelling pelo que ele pensou, e não apenas considerar seu pensamento meramente um precursor de Hegel (MATTHEWS, 2011; PUENTE, 2003; VIEIRA, 2007).

Em nossa pesquisa, não se tem como foco conceitos de filosofia da natureza, tal como feito por Assumpção, Beiser, Gonçalves e Schlanger, ou no diálogo entre a Naturphilosophie e as filosofias atuais, como feito por Heuser-Kessler. Nossa metodologia consiste num estudo diacrônico e comparativo, no qual confrontamos o pensamento de Schelling com o de Moltmann (nascido em 1926), tendo em mente a seguinte pergunta: como os dois pensadores, um filósofo e um teólogo, pensam a relação entre ser humano e natureza? Acrescenta-se que nosso texto envolve uma proposta de diálogo entre a filosofia de Schelling e a teologia, o que é raro, mas já foi feito por Lee (2010) e, no Brasil, por Leal (2015).

\section{A natureza e o ser humano em Schelling}

A dependência em relação à natureza $(\operatorname{IphN}, \mathrm{p} .111)^{18}$ é um tema importante na reflexão de Schelling. Sua filosofia da

$18 \quad$ Todas as traduções dos trechos citados são de nossa responsabilidade, e as obras de Schelling serão indicadas por siglas e paginação segundo a Edição histórico-crítica (HkA) para os textos anteriores a 1801ou de acordo com as Obras Completas (SW) para os textos posteriores a 1801, cuja edição ainda está em andamento na $H k A$. No caso de Moltmann, utilizamos quando 
natureza resgata uma concepção dinâmica da physis, tal como nos Antigos, mas também considera vários resultados da ciência moderna (GRANT, 2010, p. 61). O mundo natural é pensado como portador de inteligência própria, que se desenvolve a partir do inorgânico e se eleva ao orgânico. No ser humano, há um novo desenvolvimento natural, a consciência de si, uma espécie de "despertar" de um estado de aconsciência $(A D, \S$ 63, p. 364-366).

Schelling é um dos raros filósofos modernos a pensar que o ser humano não possui um papel de dominação da natureza, mas que precisa dela para sua existência. A instrumentalização do mundo natural pelo ser humano é uma atitude que, além de não reconhecer a limitação do próprio humano, separa ele da natureza, o que resulta numa concepção dualista de mundo. O mundo moderno, para Schelling, é o mundo das contradições, diferente do mundo antigo, o da unificação, de modo que o dualismo marca o mundo moderno, em contraposição à unidade do mundo antigo (VM, p. 272s).

A filosofia se inicia com a pergunta pela natureza, por um mundo supostamente exterior; e ao passar a considerar o representado como exterior ao sujeito, os filósofos foram se distanciando cada vez mais do mundo natural e aderindo ao modo dualista de se pensar o mundo. Uma filosofia da natureza como a de Schelling resgata a unidade entre subjetivo e objetivo, mostrando que não há um mundo "fora" de nós, mas que somos um só com o mundo (IphN, p. 69-75).Para Schelling, apenas a partir de um ponto de vista orgânico seria possível

disponível, a tradução inglesa ou portuguesa da obra. Lista de abreviaturas: Kant: KU - Kritik der Urtheilskraft; MadM -Muthmasslicher Anfang der Menschengeschichte. Moltmann: DC-Deus na Criação; JP: Justiça que promove a paz; DH - Direitos humanos, direitos da humanidade e direitos da natureza; LivG - The living Godandthefullnessoflife; EspV - Espírito da Vida: uma pneumatologia integral. Schelling: AD-Allgemeine Deduction des dynamischen Processes; AEN - Aphorismen zur Einleitung in die Naturphilosophie; Einl — Einleitung zu seinem Entwurf eines Systems der Naturphilosophie; EE - Erster Entwurf eines Systems der Naturphilosophie;IPhN — Ideen zu einer Philosophie der Natur; ÜdV-Ueber das Verhältnis der bildenden Künste zu der Natur; VM —Vorlesungen über die Methode des akademischen Studiums; WS - Von der Weltseele. 
romper com os dualismos oriundos do ponto de vista moderno sobre o sujeito (MATTHEWS, 2011, p. 1).

Após Descartes, foram raras exceções ao dualismo: Spinoza e Leibniz, tendo sido este ainda apropriado de modo dualista. A filosofia crítica de Kant e a doutrina da ciência de Fichte mantiveram o dualismo e aprofundaram a subjetividade, chegando à negação da natureza em prol de uma afirmação radical do eu pensante. Kant chega a afirmar que o ser humano é o único ser cujo fim de sua existência é a si mesmo, aquele capaz de determinar fins por meio da razão, e só ele pode ser ideal de beleza (KANT, KU, §17, p. 233). O ser humano é, para o filósofo de Königsberg, verdadeiramente fim da natureza, privilegiado sobre os outros animais, simples meios para sua nutrição e sobrevivência (KANT, $M A d M$, p. 114). No idealismo kantiano, a teleologia na natureza se reduz ao subjetivo, a uma mera interpretação do eu, e não é vista como o próprio ser da natureza (HÖSLE, 1991, p. 55).

Na doutrina da ciência de Fichte, mesmo o ato de por algo fora do eu, por exemplo, conceber um fenômeno da natureza como o magnetismo, trata-se de algo a serviço do eu, de modo que a natureza só existe na medida em que a subjetividade se opõe a ela, ou se põe a utilizá-la para seus próprios fins. Nesse contexto, a filosofia moderna, para Schelling, será vista como dualista e mecanicista, conduzindo à "aniquilação da natureza", que consiste não só em uma destruição literal dela, mas em limitá-la a qualidades e limitações, privando-a de subjetividade e autodeterminação (VM, p. 273ss). A natureza passa a ser apenas algo mensurável e objeto de dominação, um instrumento para os humanos.

Um ponto significativo na concepção schellinguiana de natureza e na crítica à instrumentalização da mesma se dá no contexto da discussão da ideia de imitação na arte, a mímesis ${ }^{19}$. Ao criticar concepções instrumentais da natureza, o filósofo diz que um conceito errôneo de natureza leva à imitação de uma natureza sem vida e sem autonomia (ÜdV, p. 293ss), aludindo a Johann Hamann. Para este, a filosofia moderna trata a natu-

19 Um exame detalhado desse ponto está em Assumpção, 2017. 
reza como um obstáculo a se remover, exigindo que se imite a natureza para renovar o prazer de se "assassinar" a natureza, não só como apresentada imediatamente, mas também como representada nas obras de arte (HAMANN, 1762, p. 188s). Uma época em que a ciência maltrata a natureza seria, para Hamann e para Schelling, um tempo no qual a arte não conseguiria fornecer uma imagem bela da natureza. Assim, só o artista que conseguisse reconhecer a grandeza da physis seria capaz de apresentar obras de arte dignas de imitá-la.

A proposta de Schelling envolve reconhecer a natureza como autônoma; autárquica e incondicionada. Autônoma por ser legisladora das próprias leis; autárquica, por ser auto-organizadora, sem necessidade de algo externo a ela para tal; incondicionada como decorrência das duas propriedades anteriores, ou seja, a natureza é a própria liberdade em seu exercício, não havendo dependência dela em relação a uma causa externa (EE, p. $81 ; 276 n$ ).A natureza é concebida como produtividade e devir constante, só que não produtividade pura; mas também produto, uma vez que ela é capaz de controlar seu fluxo produtivo mediante uma "desaceleração" que gera produtos naturais, tanto as formas orgânicas quanto as inorgânicas (EE, p. 78ss; Einl, p. 29ss).

Nesse sentido, é significativa a crítica à teleologia kantiana (IPhN, p. 94-97), que recorre à ideia de um autor da natureza, ainda que só como hipótese ou princípio reflexivo (KANT, $K U \S \S$ 74-77, p. 395-409): atribuir à natureza um autor é, para Schelling, tirar dela sua autodeterminação e liberdade. Em termos teológicos, isso significa que o filósofo recusa a ideia de criação, pensando o absoluto como o todo da realidade, no estilo de Spinoza. O apelo a Spinoza se traduz, em Schelling, como identidade originária entre natureza e espírito, entre objetivo e subjetivo, real e ideal, eu e não-eu, consciência e aconsciente, de modo que "A natureza deve ser o espírito visível, o espírito, a natureza invisível" (IPhN, p. 107). Esses polos que a consciência humana apreende dualisticamente remetem, na verdade, a uma indiferenciação entre todas as coisas, ressaltando uma tendência panteísta no filósofo. 
Nesse contexto, mostram-se de grande valia as considerações de Vittorio Hösle sobre ecologia e filosofia moderna. Para este filósofo, é significativo que a busca de uma filosofia anticartesiana que não contraponha dialeticamente a natureza à subjetividade se liga ao retorno à física antiga, especialmente à teleologia aristotélica (pensa-se aqui em Leibniz, Schelling e Hegel). Em geral, os críticos mais significativos da modernidade possuíram conhecimento profundo da filosofia antiga, ao contrário dos pais da subjetividade moderna — Descartes, Kant e Fichte (HÖSLE, 1991, p. 56).

Na filosofia de Schelling, a natureza não é só animada em sua forma orgânica, mas é espírito em si, algo cujo cerne ou telosé a subjetividade, que se explicita durante um longo processo. A natureza é, nessa concepção, imagem do absoluto, na qual o bem, o belo e a verdade convergem, havendo papel especial para o ser humano como ponto culminante e também imagem do absoluto, mas não de um absoluto que ele mesmo constrói (HÖSLE, 1991, p. 56):

(...) o homem é, como foi dito, de um lado originado da natureza e, nessa medida, uma parte da natureza; de outro lado, como único capaz do insight acerca do princípio da natureza e de si mesmo, definitivamente algo que transcende a natureza, de fato, o outro da natureza. Exatamente essa ambivalência do homem me parece o enigma principal em toda teoria das relações entre a natureza e o homem (HÖSLE, 1991, p. 48).

Embora valorizando o pensamento ecológico, o trecho de Hösle indica um ponto importante nessa questão: ainda que o ser humano seja parte da natureza, há um lugar especial para ele - que não deve, no entanto, ser um lugar de dominação. Há uma tensão entre o ser humano ocupar um lugar especial na natureza e não dominá-la, o que se reflete em Schelling. Tradicionalmente, a filosofia da natureza de Schelling foi vista como elemento de crítica à filosofia moderna e ao antropocentrismo. Todavia, o filósofo em questão pensa os animais como objetos desprovidos de eu (EE p. 197), ou como "sonâmbulos incessantes” (AEN, § 72, p. 156), que não agem por conta própria. 
O agir dos animais, para Schelling, é tido por um agir aconsciente, que não se reconhece no que faz (SHAW, 2016, p. 79-81), de modo que não se pensa nos animais como agentes, mas se lhes confere um fundamento objetivo como que atuante através deles, havendo uma engenhosidade nas ações dos animais, principalmente as oriundas dos impulsos artísticos, ligados à construção de colmeias, ninhos, formigueiros, e à confecção de teias (EE, p. 101-103;Einl, p. 29ss;WS, p. 208217). Schelling consegue, com suas concepções da filosofia da natureza, diminuir a diferença entre animal e humano, vendo mais uma relação de continuidade que uma separação radical. Mesmo a consciência, o grande diferencial entre humano e não humano, desenvolve-se gradativamente ao longo das espécies, mantendo a máxima comum a pensadores tão distintos quanto Leibniz, Kant, e mesmo Darwin, segundo a qual "a natureza não dá saltos".

O antropocentrismo filosófico toma como ponto de partida a diferença entre humanos e não-humanos, e na base da distinção, o antropocentrismo pressupõe que os humanos detêm domínio sobre outros animais, ou que podem usá-los para fins humanos e, diante disso, os humanos não lhe devem obrigações ou direitos. Apesar de Schelling criticar a ideia de que animais são máquinas, ele afirma o antropocentrismo por meio da diferença entre o mundo humano, elevado espiritualmente pela consciência de si, liberdade e intuição intelectual, e o mundo animal, regido por impulsos e forças naturais (SHAW, 2016, p. 81-89). A crítica de Shaw é válida e nos mostra as limitações de todo pensamento filosófico inerente ao tempo em que ele pertence. Não obstante, a filosofia de Schelling ainda fornece elementos para reflexões sobre ecologia, o lugar do ser humano na natureza e sua relação com ela. Outro campo em que podemos encontrar essa temática é a teologia de Moltmann.

\section{A questão ecológica em Moltmann}

Jürgen Moltmann (1926*) é um teólogo protestante alemão que se dedicou a pensar a questão da natureza em sua teologia e, consequentemente, a questão ecológica na atuali- 
dade. Suas obras são marcadas por uma crítica à concepção mecanicista do mundo que advém com a época Moderna e que vê a natureza somente como algo a ser utilizado e explorado pela humanidade.

Pensar a natureza dentro de um escopo teológico não é algo novo. A tradição bíblica, desde o Pentateuco, fala a respeito da Criação por vontade divina nos primeiros capítulos de Gênesis, bem como das leis dadas ao povo hebreu para o cultivo e manuseio da terra, que constam nos Códigos da Aliança e no Código de Santidade do povo hebreu (GOMES, 2013).

No entanto, ao longo da história, podemos perceber que teólogos e teólogas não se preocuparam muito em abordar os problemas ecológicos advindos do pensamento moderno, focando mais em uma teologia da criação em seus aspectos dogmáticos, mostrando Deus como aquele que cria o mundo para o deleite da humanidade e domínio desta sobre aquele, o que, obviamente, também é fruto do pensamento moderno.

\subsection{A criação no Espírito}

Na contramão do pensamento moderno encontramos o pensamento de nosso teólogo que desenvolve sua doutrina da criação buscando responder à seguinte pergunta: "o que significa a fé no Deus Criador e neste mundo como sua Criação face à crescente exploração industrial e à irremediável destruição da natureza? (MOLTMANN, DC, p. 9; JP, p. 113-125; DH, p. 135-152)".

Para se responder essa questão teologicamente, e dentro de uma perspectiva ecológica, Moltmann pensa a partir do Espírito Santo que, na tradição cristã, é a fonte de vida e, como diz nosso teólogo, o "amante da vida", estando dessa forma em cada ser criado e permeando toda a sua Criação (MOLTMANN, DC, p. 10).

Se o Espírito permeia toda a Criação, então pensar a imanência de Deus no mundo torna-se o caminho mais adequado, fazendo-se necessário entender Deus como o Espírito do Universo, e a Criação como a história dos efeitos do Espírito 
de Deus, estando em total relação com sua própria presença (MOLTMANN, DC, p. 33). Essa criação no Espírito e pelo Espírito faz com que o espírito ${ }^{20}$ seja pensado, quando em relação à natureza, como as formas de organização e os modos de comunicação de sistemas abertos ${ }^{21}$ (cf. MOLTMANN, DC, p. 37).

Há um crescente de complexidade nessas formas de organização que começam por matéria sem forma, passando por formas de sistemas vivos, multifacetárias simbioses vivas e por pessoas e populações humanas até chegar ao sistema ecológico 'Terra', ao Sistema Solar, à Via láctea e ao conjunto de galáxias do Universo. Nesse sentido, no pensamento moltmanniano, há uma tendência do espírito para sistemas cada vez mais complexos, tanto por meio da junção dos diversos sistemas vivos abertos que formam formas de vida simbióticas, como também através dos desdobramentos de vida mais rica na terra nova do possível e do futuro (MOLTMANN, DC, p. 37), o que abre novas perspectivas para se pensar a própria evolução em perspectiva teológica.

\subsection{O Espírito e a concretude do mundo}

Embora possa parecer meramente especulativo, é interessante pensar no caráter realista do pensamento de Moltmann. Ao falar acerca do Espírito, não fala meramente de algo

20 Uma observação se faz necessária. Ao usarmos a palavra espírito com letras minúsculas, consideramos o conceito moltmanniano de espírito cósmico (que se assemelha com o conceito das energias divinas da teologia cristã ortodoxa), que deve ser pensado de maneira diferente ao Espírito da salvação e nova criação de todas as coisas que é o Espírito Santo de Deus. O Espírito Santo pode transformar o espírito cósmico e fazê-los conforme Cristo, mas a diferenciação entre espírito cósmico e Espírito de Deus deve ser mantida. Cf. MOLTMANN, DC, 1993, p. 374-375. Embora em MOLTMANN, Jürgen. O Espírito da Vida: uma pneumatologia Integral. 2010, p. 215, Moltmann fala a respeito do Espírito cósmico, consideramos que o que tem em mente é o Espírito Santo como Criador da vida e é vida em tudo que criou. Nesse sentido, não é identificado com a vida ordinária, mas antes com a própria vida. Aqui, o conceito de energia divina possui um papel fundamental para o entendimento desse conceito em Moltmann.

$21 \quad$ O sistema aberto é definido por Moltmann como aquilo que é aberto para as possibilidades de seu futuro. Nesse sentido, a humanidade, sua história, a criação e o próprio cosmos é um sistema aberto. 
transcendente e que não tem nada a ver com o mundo e a corporeidade. Muito pelo contrário, o Espírito se faz presente na corporeidade da natureza, animando-o e vivificando-o, rumo à nova criação de todas as coisas.

Para Moltmann, é através do Espírito que estamos ligados social e culturalmente com outras pessoas, e esta ligação é um sistema organizado aberto. Com isso em mente, considera que o Espírito pode ser definido como Espírito da comunhão humana, uma vez que também por esse Espírito estamos ligados com o meio-ambiente natural. Dessa forma, Moltmann define esta ligação como ecossistema espiritual. Através do Espírito, sociedades humanas estão ligadas como sistemas parciais com a terra (MOLTMANN, DC, p. 38).

As pessoas são, dessa forma, participantes e subsistemas do sistema da vida cósmica e do Espírito divino que nele habita. Moltmann ainda propõe que a consciência humana do Espírito seja estendida a um maior número de formações do Espírito e a um ampliar da consciência individual conforme os princípios de organização do Espírito (diacrônica e sincrônica) até uma consciência social ecológica cósmica e divina. Assim, a consciência individual entra em formas de organização do Espírito mais elevadas, complexas e multifacetárias e alcança intercambio de vida mais diferenciado e elevado e, dessa forma, o Espírito individual, divino cósmico e social alcança maior e mais larga consciência de si próprio na pessoa humana. Com isso, Moltmann não vê criação e evolução como contraditórias, mas como conceitos interligados e complementares, de maneira que há uma criação da evolução e uma evolução da criação. Assim, o conceito de evolução deve ser entendido como conceito básico da automovimentação do Espírito divino da criação (MOLTMANN, DC, p. 39).

Se isso ocorre com toda a criação, então claramente a questão da natureza também entra em cena. O homem, como também criado juntamente com a natureza, está em relação íntima com ela, sendo também seu produto. O que acontece com a natureza acontece também com a pessoa humana e com toda a Criação. 
Contrariamente à visão tradicional cristã que pensa a humanidade como "coroa" da Criação divina, Moltmann pensa essa humanidade como a mais dependente de todas, uma vez que é criada após todo o restante que lhe dá condições de subsistir no planeta (cf. MOLTMANN, LivG, p. 81). Destruir a natureza, além de ser um ato contra Deus que a criou, torna-se também como um movimento de autodestruição.

A nosso ver, essa visão entra em choque com visão tecnicista e moderna do mundo com relação à natureza. Enquanto no mundo moderno a natureza deve ser vista como um objeto à parte de nós, o qual devemos explorar como reflexo de um entendimento de que ser imagem de Deus é dominar a terra, entender a natureza como próprio sujeito da criação nos faz percebê-la como também uma imagem do mundo criado por Deus. Como diz Moltmann,

Neste sentido, é importante para a autocompreensão da pessoa que ela se compreenda primeiramente não como sujeito em relação à natureza, e teologicamente como imagem de Deus, mas que ela se compreenda primeiramente como produto da natureza e também teologicamente como imagem do mundo (MOLTMANN, DC, p. 82).

Com esse pano de fundo, a experiência natural adquire novo conceito. Experiências acontecem conosco e nós as percebemos e as recebemos. Elas se condensam em nossas percepções e a partir dessas concepções formamos outras com as quais identificamos e classificamos os acontecimentos (MOLTMANN, DC, p. 82).

Assim, e de acordo com o novo paradigma ecológico, não se vê a Terra como algo a ser dominado, antes como nossa casa comum e, de acordo com a carta da Terra, "uma comunidade de vida única", cuja "proteção da vitalidade, diversidade e beleza da Terra é um dever sagrado" (Carta da Terra, 2000), o que, obviamente, segue na contramão de toda visão contemporânea de instrumentalização da natureza. 


\section{Considerações Finais}

É possível perceber traços convergentes e divergentes ao elucidarmos os pensamentos de Schelling e Moltmann. No que tange à convergência, nota-se que ambos os autores criticam de forma veemente a instrumentalização da natureza como fruto do advento da Modernidade, que tem como possível consequência tanto a aniquilação da natureza (Schelling) quanto a autodestruição da própria humanidade (Moltmann). Com isso, podemos dizer que ambos os autores fazem uma crítica a certa visão de progresso que é trazida com todo o movimento Moderno.

Quanto às divergências, essas ocorrem em nível mais ontológico. Enquanto em Schelling não há diferenciação radical entre espírito e natureza, devendo esta ser vista como sistema fechado em si e que não necessita de nada que lhe é externo para sua origem, ao passo que, em Moltmann, percebe-se a presença de um Espírito que é Criador e que dá sentido a essa natureza, colocando a humanidade como parte desse todo e, ainda, como parte mais fraca desse todo que é a Criação. Enquanto em Schelling, é possível perceber o monismo, em Moltmann, a diferenciação entre Criador e criatura se fazem fundamentais para se pensar a relação humano e natureza.

\section{Referências}

ASSUMPÇÃO, G. "Crítica do juízo teleológico e organismo em Kant e Schelling". Doispontos: Curitiba, São Carlos, vol. 2, n. 02 (2015): 123-135. Disponivel em: http://ojs.c3sl.ufpr.br/ojs2/index.php/ doispontos/article/view/38898/26528. Acesso em: 23 Dez 2015.

ASSUMPÇÃO, G. "A pintura abstrata e Schelling: atravessar a "pele da natureza" ". Princípios (UFRN), v. 24, n. 45, (2017): 5979. Disponível em: https://periodicos.ufrn.br/principios/article/ view/11877. Acesso em: 22 Jan. 2018.

BARBOZA, J. Infinitude subjetiva e estética: Natureza e arte em Schelling e em Schopenhauer. São Paulo: Ed. UNESP, 2005.

BEISER, F. German Idealism: The Struggle against Subjectivism, 18711801. Cambridge, London: Harvard University Press, 2002.

Carta da Terra, 2000. Disponível em http://www.mma.gov.br/estruturas/agenda21/_arquivos/carta_terra.pdf.Acesso em: 03 abr. 2018. 
CHO, Young-Chun. NaturalsSubjekt. Schellings Naturphilosophie und ihre ökologische Bedeutung. Saarbrücken: VDMVerlag Dr. Müller, 2008.

GONÇALVES, M. "A relação dialética entre consciente e inconsciente na filosofia da natureza do jovem Schelling". Síntese - Revista de Filosofia, v. 42, n. 133 (2015a): 263-278. Disponível em: http://faje. edu.br/periodicos2/index.php/Sintese/article/view/3333/3443. Acesso em 23 Dez. 2015.

GONÇALVES, M. "Schelling: filósofo da natureza ou cientista da imanểncia?". In: PUENTE, F. R.; VIEIRA, L. A. (Orgs.). As filosofias de Schelling. Belo Horizonte: Editora UFMG, 2005, p. 71-90.

GOMES, Alessandro Martins. A legislação de Israel em relação ao uso da terra. In: Anais do Salão de Pesquisa da Faculdades EST. São Leopoldo: EST, v. 12, 2013, p. 141-162.

GRANT, I. H. (2010): F.W.J. Schelling, 'On the World Soul', Translation and Introduction. In Mackay, R., Ed (2010): Collapse vol VI, Geo/Philosophy (6).Urbanonce, p. 58-95.Disponível em: http:// eprints.uwe.ac.uk/12310/2/Grant.pdf. Acessoem: 11 Jun 2016.

GRANT, I. H. Philosophies of Nature after Schelling. London/New York: Continuum, 2006.

HAMANN, J. G.Aesthetica in Nuce.EineRhapsodie in KabbalisticherProse.In. HAMANN, J. G.Kreuzzüge des Philologen. Königsberg, Kanter Verlag, 1762, p. 159-220.Disponível em: https://bildsuche. digitale-sammlungen.de/index.html? $\mathrm{c}=$ viewer\&lv $=1 \&$ bandnummer $=$ bsb00074628 $\&$ pimage $=00001 \&$ suchbegriff $=\& l=$ de. Acesso em: 21 dez. 2016.

HEUSER-KESSLER, M.-L.; JACOBS, W. (Hrsg.) Selbstorganisation. Jahrbuch für Komplexität in den Natur-, Sozial- und Geisteswissenschaften, Band 5. Duncker \& Humboldt: Berlin, 1994.

HÖSLE, V.Philosophie der ökologischen Krise.Moskauer Vorträge. München: Verlag C. H. Beck, 1991.

KANT, I. Kritik der Urtheilskraft. In: Kants Werke. Akademie-Textausgabe. Band V. Berlin: Walter de Gruyter \& Co., 1968, p. 165-485.

KANT, I. Muthmasslicher Anfang der Menschengeschichte. In: Kants Werke. Akademie-Textausgabe. Band III. Berlin: Walter de Gruyter \& Co., 1968, p. 109-123.

LEAL, p. R. B. "A influência de Schelling". Revista Eletrônica Correlatio, vol. 14, n. 28 (2015): 97-116. Disponível em: https://www. metodista.br/revistas/revistas-ims/index.php/COR/article/viewFile/6344/5108.Acessoem: 07 Mar 2018.

MATTHEWS, B. Schelling's Organic Form of Philosophy: Life as the Schema of Freedom. Albany: SUNY Press, 2011. 
MOLTMANN, Jürgen. Deus na criação: doutrina ecológica da criação. Petrópolis: Vozes, 1993

MOLTMANN, Jürgen. A justiça que promover a paz. Concilium Brasil. Petrópolis, n.215, p. 113-125, Jan. 1988

MOLTMANN, Jürgen. Direitos humanos, direitos da humanidade e direitos da natureza. Concilium Brasil. Petrópolis, n.228, p. 135-152, Mar.1990.

MOLTMANN, Jürgen. The living God and the fullness of life. Geneva: WCC Publications, 2016.

MOLTMANN, Jürgen. O Espírito da Vida: uma pneumatologia Integral. Petrópolis: Vozes, 2010.

PUENTE, F. R. "Novas perspectivas sobre o idealismo alemão". Síntese - Revista de Filosofia, v. 30, n. 96 (2003): 125-130.

SCHELLING, F. W. J. Aphorismen zur Einleitung in die Naturphilosophie.In: SCHELLING, F. W.J. Sämmtliche Werke. Erste Abtheilung. Siebenter Band. Stuttgart und Augsburg: Cotta, 1860, p. 140-197. Disponível em: https://archive.org/details/smtlichewerke07p1sche. Acesso em: 23 Jun. 2016.

SCHELLING, F. W. J. Allgemeine Deduktion des dynamischen Prozesses oder der Kategorien der Physik. In: SCHELLING, F. W. J. Friedrich Wilhelm Joseph Schelling Historisch-kritische Ausgabe. Reihe I: Werke 8. Stuttgart: Frommann-Holzboog, 2004, p. 273-371.

SCHELLING, F. W. J. Einleitung zu seinem Entwurf eines Systems der Naturphilosophie. In: SCHELLING, F. W. J. Friedrich Wilhelm Joseph Schelling Historisch-kritische Ausgabe. Reihe I: Werke 8. Stuttgart: Frommann-Holzboog, 2004, p. 1-86. Reihe I: Werke 8, 2004, p. 1-86.

SCHELLING, F. W. J. Erster Entwurf eines Systems der Naturphilosophie. In: SCHELLING, F. W. J. Friedrich Wilhelm Joseph Schelling Historisch-kritische Ausgabe. Reihe I: Werke 7, 2001.

SCHELLING, F. W. J. Ideen zu einer Philosophie der Natur. In:

SCHELLING, F. W. J. Friedrich Wilhelm Joseph Schelling Historisch -kritische Ausgabe. Reihe I: Werke 5. Stuttgart: Frommann-Holzboog, 1994.

SCHELLING, F. W. J. Ueber das Verhältnis der bildenden Künste zu der Natur. In: SCHELLING, F. W.J.Sämmtliche Werke. Erste Abtheilung. Siebenter Band. Stuttgart und Augsburg: Cotta, 1860, p. 289-329. Disponível em: https://archive.org/details/smtlichewerke07p1sche. Acesso em: 19 Mar. 2016.

SCHELLING, F. W. J. Von der Weltseele - Eine Hypothese der höhern Physik zur Erklärung des allgemeinen Organismus. In: SCHELLING, F. W. J. Friedrich Wilhelm Joseph Schelling Historisch-kritische Ausgabe. Reihe I: Werke 6. Stuttgart: Frommann-Holzboog, 2000. 
SCHELLING, F. W. J. Vorlesungen über die Methode des akademischen Studiums. In: SCHELLING, F.W.J.Sämmtliche Werke. Erste Abtheilung. Fünfter Band. Stuttgart und Augsburg: Cotta, 1859, p. 207-352. Disponível em: https://archive.org/details/smtlichewerke05p1sche. Acesso em: 20 Abr. 2016.

SCHLANGER, J. Schelling et la Réalité Finie. Essai sur la philosophie de la Nature et de l'Identité. Paris: P.U.F., 1966.

SHAW, D. Z.“ 'Animals, those Incessant Somnambulists': a Critique of Schelling's Anthropocentrism". In MCGRATH, S. J., CAREW, J. (Eds.). Rethinking German Idealism. London: MacMillan Publishers, 2016, p. 77-97.

SHAW, D. Z. Freedom and Nature in Schelling's Philosophy of Art. London/NY: Continuum, 2010.

VIEIRA, L. Schelling. Rio de Janeiro: Jorge Zahar Ed., 2007.

LEE, YONG JOO. Unterwegs zum Trinitärischen Schöpfer. Die Frühphilosophie Schellings und ihre Bedeutung für die gegenwärtige Schöpfungstheologie. Berlin/New York: Walter de Gruyter, 2010.

WIRTH, J. M. The Conspiracy of Life: Meditations on Schelling and His Time. Albany: SUNY Press, 2003. 